\title{
Percepções dos gestores varejistas sobre suas competências de marketing
}

\section{Perceptions of retailers managers on their marketing competences}

\author{
Mauriceia Soares Pratissolli Guzzo ${ }^{l}$ \\ Emerson Wagner Mainardes ${ }^{2}$ \\ Rozelia Laurett ${ }^{3}$
}

\begin{abstract}
Resumo
Este estudo teve como objetivo principal identificar os fatores que compõem as competências de marketing no varejo. A pesquisa, de natureza descritiva e quantitativa, utilizou como instrumento para a coleta de dados um questionário estruturado, que foi aplicado junto a 199 gestores varejistas pertencentes ao mercado varejista de produtos e serviços. De maneira geral, infere-se que os gestores varejistas consideram a imagem da loja e a qualidade do produto/serviço como sendo as principais competências de marketing de suas empresas, o que resulta em uma atenção efetiva com a imagem da empresa. Por fim, identificou-se quatro fatores que sistematizaram as competências de marketing no varejo: orientação para o mercado, capacidades internas, ambiente de negócios e estrutura/processos. Como contribuições teóricas, destacamse o agrupamento dos vinte atributos das competências de marketing em quatro fatores e o não analisar especificamente o setor supermercadista. $\mathrm{Na}$ prática, estes quatro fatores podem ser utilizados pelos gestores varejistas para definir seus novos planos de marketing e novos investimentos em treinamento e desenvolvimento.
\end{abstract}

Palavras-chave: Varejo; competências de marketing; gestores varejistas

\begin{abstract}
This study objective to identify the factors that make up the marketing competences in retail. The research, descriptive and quantitative, used as a tool for data collection a structured questionnaire applied at 199 retail managers belonging to the retail market products and services. In general, it is inferred that retailers managers consider image store and product quality/service as the main marketing competences of their companies, resulting in an effective care with the company's image. Finally, it identified four factors that systematized marketing skills in retail: market orientation, internal capabilities, business environment, structure/processes. Theoretical contributions include grouping the twenty attributes of marketing competences into four factors and not analyzing specifically the supermarket sector. In practice these four factors can be used by retail managers to define their new marketing plans and new investments in training and development.
\end{abstract}

Key-words: Retail; marketing competences; retail managers.

Mestre em Administração (FUCAPE BUSINESS SCHOOL) E-mail: mauriceiaguzzo@gmail.com

${ }^{2}$ Doutor em Administração (FUCAPE BUSINESS SCHOOL) E-mail: emerson@fucape.br

${ }^{3}$ Mestre em Administração (FUCAPE BUSINESS SCHOOL) E-mail: rozelialaurett@gmail.com

Agradecimentos: Esta pesquisa foi apoiada pelo CNPq/Brasil (projeto 303669/2015-2) e pelo FCT/Portugal (projeto NECE/UBI - UID/GES/04630/2013).

Artigo recebido em: 19 de maio de 2017. Artigo aceito em 20 de novembro de 2017. 


\section{Introdução}

A modernidade trouxe consigo a mudança no comportamento e nos hábitos de compras dos consumidores (BARKI; BOTELHO; PARENTE, 2013). A tradicional loja física deixou de ser o único meio de se fazer compras e passou a funcionar como um dos muitos pontos de contato entre os consumidores e o varejo (DELOITTE, 2013). Por isso, o varejo, que opera em um ambiente potencialmente competitivo,precisa criar uma diferenciação que possa ser percebida pelos clientes (PANIGYRAKIS; THEODORIDIS, 2007).

Nesse cenário, torna-se necessário que o setor varejista busque observar e compreender as percepções dos clientes, agregando real valor ao produto ou serviço, gerando, assim, a vantagem competitiva (ZEN, 2005). Uma das estratégias que o varejista pode utilizar para obter tal vantagem é aplicar as competências de marketing, pois são importantes para gerar vantagem competitiva sustentável (MELAIA; ABRATT; BICK, 2008). As competências de marketing são compostas por habilidades e atividades que a empresa pode executar melhor que os seus concorrentes e que permite agregar valor aos produtos ou serviços oferecidos aos consumidores finais (DAY, 1994).

Ressalta-se que o reconhecimento e o desenvolvimento dessas competências de marketing tendem a gerar um impacto no desempenho da empresa, e ainda podem melhorar os níveis de eficácia e manter a vantagem competitiva no mercado (O'DISCROLL; CARSON; GILMORE, 2000). Observou-se que, apesar de sua importância estratégica, a maioria das pesquisas anteriores aborda as competências de marketing com foco no varejo supermercadista (FARHANGMEHR; MARQUES; SILVA, 2000; PANIGYRAKIS; THEODORIDIS, 2007; QUEIROZ; SOUZA; GOUVINHAS, 2008; RAMAKRISHNAN, 2010).

Assim, este estudo terá como foco analisar o setor varejista, englobando o comércio varejista e o comércio varejista ampliado a partir da perspectiva dos gestores. Sendo o comércio varejista aqui considerado como o setor que vende produtos ou serviços ao consumidor final para uso familiar e/ou pessoal, e tendem a englobar um alto número de empresas de pequeno porte (IBGE, 2017). Já o comércio varejista ampliado agregou ao ramo varejista os "veículos, motocicletas, partes e peças" e os "materiais de construção" que também fazem parte do ramo atacadista (IBGE, 2013). Assim, nesta pesquisa, foi considerada a percepção dos gestores do comércio varejista e 


\section{GUSSO;MAINARDES; LAURETT}

do comércio varejista ampliado, ou seja, ambos são comércios varejistas e que têm como objetivo vender produtos e/ou serviços para o consumidor final.

Para tal, este estudo visou responder a seguinte questão de pesquisa: Quais os fatores que compõem as competências de marketing no varejo? Portanto, esse estudo teve como objetivo identificar os fatores que compõem as competências de marketing no comércio varejista e no comércio varejista ampliado. Assim, foi desenvolvido um modelo neste estudo abordando as competências de marketing (CM) que poderá ser utilizado na formulação de estratégias voltadas para o marketing de varejo em geral, e não especificamente para os supermercados.

Desta forma, como contribuição para a teoria, este estudo deu continuidade às pesquisas sobre marketing no varejo ao buscar perceber as competências de marketing a partir da perspectiva dos gestores do varejo tradicional e ampliado brasileiro, e não com foco específico no setor varejista supermercadista. Outra contribuição deste estudo é pesquisar o contexto das empresas varejistas de diferentes classificações (empreendedor individual, microempresa, pequena empresa, média empresa e grande empresa) realizando assim uma análise do varejo em geral.

Para a prática, este estudo pode ser utilizado pelas empresas a fim de averiguar em quais competências de marketing os gestores ou as empresas têm investindo mais, ressaltando que todas as competências tendem a ser relevantes para o processo de diferenciação e vantagem competitiva no mercado. Ainda, estas informações podem ser utilizadas pelos setores de treinamento e desenvolvimento das empresas varejistas, a fim de verificar em quais áreas é necessário qualificar os gestores varejistas ou em quais competências de marketing necessita investir e desenvolver.

Assim, para atender ao objetivo deste trabalho, buscou-se primeiro entender o cenário do mercado varejista e do marketing de varejo, e a seguir foram apresentadas as competências de marketing e os seus respectivos atributos. Em seguida, foi realizada uma pesquisa de campo junto a 199 gestores de empresas varejistas para verificar a utilização das competências de marketing em suas respectivas empresas. Após, analisou-se os dados coletados por meio da caracterização da amostra, estatística descritiva e da análise fatorial exploratória. Pode-se concluir que os 20 atributos identificados resultaram na composição de quatro fatores que compõem as competências de marketing do setor varejista: orientação para o mercado, capacidades internas, ambiente de negócios, estrutura e processos.

Revista Eletrônica Gestão e Serviços v.8, n. 2, pp. 2080-2104, Julho/Dezembro 2017.

ISSN Online: 2177-7284 e-mail: regs@metodista.br 


\section{Referencial teórico}

\subsection{Mercado varejista}

Este estudo buscou pesquisar o mercado varejista, composto pelo comércio varejista e comércio varejista ampliado (IBGE, 2014). Segundo o IBGE (2017), “[...] no comércio varejista, observa-se um alto número de estabelecimentos de pequeno porte em termos de pessoal ocupado, e cujas vendas destinam-se ao consumidor final para uso familiar ou pessoal". Já o comércio varejista ampliado agrega os "veículos, motocicletas e peças" e "material de construção" que ao mesmo tempo também fazem parte do setor atacadista (IBGE, 2013).

Desta forma, pode-se verificar que o mercado varejista representa um segmento importante, pois é por meio dele que os produtos ou serviços chegam ao consumidor final (BARKI; BOTELHO; PARENTE, 2013). Além disso, por manter contato e relacionamento permanente com o cliente final, o varejista é tratado como uma etapa decisiva dentro do marketing e, como tal, deve ser analisado estrategicamente (TOLEDO; NEVES; MACHADO FILHO, 1997).

No início do século XXI, o varejo brasileiro passou por transformações, como, por exemplo, o crescimento dos shoppings centers, que foi um reflexo da busca do consumidor por praticidade, comodidade e a ampliação das exigências nas decisões de compra. Essas mudanças representam para os varejistas, ao mesmo tempo, um desafio relacionado ao alinhamento entre os seus canais físicos e virtuais e uma oportunidade, pois se pode incrementar a entrada de receitas e ampliar sua participação no mercado (DELOITTE, 2013). Esse incremento de receitas, consequentemente, pode representar um aumento no poder de compra das empresas varejistas, proporcionando investimentos em gerenciamento de qualidade e em melhores sistemas de informação, permitindo às grandes varejistas absorverem os papéis que tradicionalmente eram desempenhados pelos atacadistas (CARSON, 2003).

Por outro lado, esse crescimento não garante vantagem competitiva sustentável, pois esta surge a partir da capacidade de desenvolver planos de marketing eficazes e que permitam que a empresa se torne mais ágil e adaptável ao mercado volátil do século XXI (BROOKSBANK, 1999; TOFTEN; HAMMERVOLL, 2010). Assim é possível perceber que uma saída é investir nas competências de marketing, pois estas tendem a contribuir para criação de uma vantagem competitiva, porque o valor gerado por elas

Revista Eletrônica Gestão e Serviços v.8, n. 2, pp. 2080-2104, Julho/Dezembro 2017. ISSN Online: 2177-7284 e-mail: regs@ metodista.br 


\section{GUSSO;MAINARDES; LAURETT}

pode ser apropriado pela empresa (GUENZI; TROILO, 2006). Portanto, é necessário que os varejistas estejam cientes da relevância do marketing de varejo e das competências de marketing como estratégias indispensáveis para gerar a vantagem competitiva sustentável (MELAIA; ABRATT; BICK, 2008; TOFTEN; HAMMERVOLL, 2010) e o seu impacto no desempenho da empresa (O'DISCROLL; CARSON; GILMORE, 2000).

\subsection{Marketing de varejo e as competências de marketing}

O marketing de varejo é composto por variáveis denominadas "composto varejista" ou 6 P's - Mix de Produtos, Preços, Promoção, Apresentação, Pessoal e Ponto, as quais agregam e articulam os fatores controláveis da empresa, buscando conquistar a preferência do consumidor (PARENTE, 2007). Ressalta-se que existe relação direta entre as variáveis do composto varejista e as decisões de marketing (variedade de linha, qualidade, sinalização, departamento, atendimento, acesso e outras) no processo de compra do consumidor, sendo que essa relação tem como função auxiliar o varejista na tomada de decisão, visando satisfazer adequadamente as necessidades de seus clientes e, consequentemente, obtendo a lucratividade esperada (QUEIROZ; SOUZA; GOUVINHAS, 2008).

Portanto, a consolidação do setor de varejo e a migração de um poder significativo ao longo da cadeia de abastecimento permitiram que, gradualmente, os varejistas obtivessem mais controle sobre os processos de marketing e, ao mesmo tempo, os obrigou a adotar posturas estratégicas frente à concorrência (CONSTANTINIDES, 2006). Entretanto, de acordo com Ramarao (2012), para que a empresa possa lidar com a concorrência e explorar novas oportunidades de mercado, torna-se necessário que a mesma tenha e aplique determinadas competências, tais como as competências de marketing.

As competências de marketing são compostas por habilidades singulares e atividades que a empresa pode executar melhor que seus concorrentes e que permitem agregar valor ao produto ou ao serviço oferecidos (DAY, 1994). E representam a mais importante e necessária competência para o varejo, que vende seus produtos/serviços diretamente aos clientes/consumidores finais (RAMARAO, 2012). Por meio da 


\section{GUSSO;MAINARDES; LAURETT}

utilização das competências de marketing, as empresas tendem a ter um maior número de informações sobre os seus clientes e os concorrentes, como, por exemplo, a mudança da preferência nos gostos dos consumidores (WIRTZ; PELZ; ULLRICH, 2011).Estas informações podem ser utilizadas pelas organizações no processo de tomada de decisão e podem influenciar positivamente no desempenho das empresas.

As competências de marketing referem-se às habilidades únicas de uma organização, necessárias para conhecer os clientes e proporcionar os benefícios esperados por eles, sendo que tais habilidades devem ser associadas diretamente ao desempenho da organização em relação aos seus concorrentes (WOODSIDE; SULLIVAN; TRAPPEY, 1999). Portanto, a empresa que possui competências de marketing orienta-se estrategicamente para o mercado, mantendo o foco no cliente e inserindo internamente o conceito e a importância das ações de marketing (HOOLEY et al., 2005).

Nesta pesquisa, foram utilizadas as 20 competências de marketing, baseadas no estudo de Conant, Mokwa e Varadarajan (1990) e para cada competência foi desenvolvido um atributo. Os atributos apresentados foram identificados a partir da análise da literatura correspondente, sendo mantida a ordem proposta no estudo de Conant, Mokwa e Varadarajan (1990).

Optou-se pelos 20 atributos definidos por Conant, Mokwa e Varadarajan (1990) por estes serem os mais utilizados nas pesquisas de marketing, especificamente tratando-se das competências de marketing. Sendo assim, os atributos, as competências de marketing e os seus respectivos autores foram apresentados por meio do quadro 1 .

\begin{tabular}{|c|c|c|c|}
\hline $\mathbf{N}$ & ATRIBUTOS & $\begin{array}{c}\text { COMPETÊNCIAS DE } \\
\text { MARKETING } \\
\end{array}$ & AUTOR(ES) /ANO \\
\hline 1 & $\begin{array}{l}\text { Relação com o } \\
\text { cliente }\end{array}$ & $\begin{array}{l}\text { Possui sólida relação com os } \\
\text { clientes, que permite conhecê-los } \\
\text { profundamente. }\end{array}$ & $\begin{array}{l}\text { Gummesson (1987); Conant, Mokwa e } \\
\text { Varadarajan (1990); Lourenço e Sette } \\
\text { (2013) }\end{array}$ \\
\hline 2 & Concorrência & $\begin{array}{l}\text { Conhece profundamente os } \\
\text { concorrentes. }\end{array}$ & $\begin{array}{l}\text { Conant, Mokwa e Varadarajan (1990); } \\
\text { Dibb (1998); Constantinides (2006); }\end{array}$ \\
\hline 3 & $\begin{array}{l}\text { Tendências do } \\
\text { varejo }\end{array}$ & $\begin{array}{l}\text { Acompanha sistematicamente as } \\
\text { tendências do varejo, para conhecê- } \\
\text { las previamente. }\end{array}$ & $\begin{array}{l}\text { Conant, Mokwa e Varadarajan (1990); } \\
\text { Ambler (2000); Burt e Sparks (2003) }\end{array}$ \\
\hline 4 & Receita de vendas & $\begin{array}{l}\text { Prevê eficazmente as vendas dos } \\
\text { produtos/serviços de seu varejo. }\end{array}$ & $\begin{array}{l}\text { Tellis (1986); Conant, Mokwa e } \\
\text { Varadarajan (1990); Indounas e } \\
\text { Avlonitis (2009) }\end{array}$ \\
\hline 5 & $\begin{array}{c}\text { Forças de } \\
\text { marketing da } \\
\text { empresa }\end{array}$ & $\begin{array}{l}\text { Tem consciência dos seus pontos } \\
\text { fortes ligados ao marketing } \\
\text { praticado. }\end{array}$ & $\begin{array}{l}\text { Zeithaml e Zeithamal (1984); Conant, } \\
\text { Mokwa e Varadarajan (1990); Toaldo e } \\
\text { Luce (2006) }\end{array}$ \\
\hline 6 & $\begin{array}{l}\text { Fraquezas de } \\
\text { marketing da }\end{array}$ & $\begin{array}{l}\text { Tem consciência dos seus pontos } \\
\text { fracos ligados ao marketing }\end{array}$ & $\begin{array}{l}\text { Zeithaml e Zeithamal (1984); Conant, } \\
\text { Mokwa e Varadarajan (1990); Toaldo e }\end{array}$ \\
\hline
\end{tabular}

Revista Eletrônica Gestão e Serviços v.8, n. 2, pp. 2080-2104, Julho/Dezembro 2017.

ISSN Online: 2177-7284 e-mail: regs@ metodista.br 


\section{GUSSO;MAINARDES; LAURETT}

\begin{tabular}{|c|c|c|c|}
\hline & empresa & praticado. & Luce (2006) \\
\hline 7 & $\begin{array}{l}\text { Planejamento de } \\
\text { marketing }\end{array}$ & $\begin{array}{l}\text { Possui capacidade técnica para } \\
\text { desenvolver o planejamento de } \\
\text { marketing. }\end{array}$ & $\begin{array}{l}\text { Conant, Mokwa e Varadarajan (1990); } \\
\text { Cousins (1991); McDonald (1992); } \\
\text { Ambler (2000) }\end{array}$ \\
\hline 8 & $\begin{array}{l}\text { Recursos para o } \\
\text { marketing }\end{array}$ & $\begin{array}{l}\text { Destina recursos necessários } \\
\text { (financeiros, tecnológicos, } \\
\text { humanos e estruturais) para que as } \\
\text { atividades de marketing possam ser } \\
\text { desenvolvidas eficazmente. }\end{array}$ & $\begin{array}{l}\text { Conant, Mokwa e Varadarajan (1990); } \\
\text { McDonald (1992); Ambler (2000) }\end{array}$ \\
\hline 9 & $\begin{array}{l}\text { Integração de } \\
\text { atividades }\end{array}$ & $\begin{array}{l}\text { Integra as atividades de marketing } \\
\text { às atividades de rotina. }\end{array}$ & $\begin{array}{l}\text { Conant, Mokwa e Varadarajan (1990); } \\
\text { McDonald (1992); Ambler (2000) }\end{array}$ \\
\hline 10 & $\begin{array}{l}\text { Segmentação do } \\
\text { público-alvo }\end{array}$ & $\begin{array}{l}\text { Possui habilidade para dividir o } \\
\text { público-alvo em grupos de } \\
\text { consumidores potenciais. }\end{array}$ & $\begin{array}{l}\text { Conant, Mokwa e Varadarajan (1990); } \\
\text { Dibb (1998); Toaldo e Luce (2006) }\end{array}$ \\
\hline 11 & $\begin{array}{l}\text { Benefícios do } \\
\text { produto/serviço }\end{array}$ & $\begin{array}{l}\text { Oferece produto/serviço atrativo e } \\
\text { com benefícios além daqueles } \\
\text { esperados pelos clientes. }\end{array}$ & $\begin{array}{l}\text { Levitt (1980); Conant, Mokwa e } \\
\text { Varadarajan (1990); Dibb (1998); Toni } \\
\text { et al. (2011) }\end{array}$ \\
\hline 12 & $\begin{array}{l}\text { Inovação em } \\
\text { marketing }\end{array}$ & $\begin{array}{l}\text { Explora eficazmente as ideias } \\
\text { inovadoras voltadas para a venda } \\
\text { de novos produtos/serviços. }\end{array}$ & $\begin{array}{l}\text { Levitt (1980); Conant, Mokwa e } \\
\text { Varadarajan (1990); Hart } \\
\text { (2003)Smigielska e Wisniewska (2016) }\end{array}$ \\
\hline 13 & $\begin{array}{c}\text { Qualidade do } \\
\text { produto/serviço }\end{array}$ & $\begin{array}{l}\text { Oferece produto/serviço com } \\
\text { qualidade superior à concorrência. }\end{array}$ & $\begin{array}{l}\text { Conant, Mokwa e Varadarajan (1990); } \\
\text { Dibb (1998) }\end{array}$ \\
\hline 14 & Promoção & $\begin{array}{l}\text { Desenvolve estratégias eficazes } \\
\text { para divulgação do } \\
\text { produto/serviço. }\end{array}$ & $\begin{array}{l}\text { Conant, Mokwa e Varadarajan (1990); } \\
\text { Nowak ePhelps (1994) }\end{array}$ \\
\hline 15 & Relações públicas & $\begin{array}{l}\text { Interage eficazmente com o público } \\
\text { externo (clientes, fornecedores, } \\
\text { meios de comunicação e outros). }\end{array}$ & $\begin{array}{l}\text { Zeithaml e Zeithamal (1984); Conant, } \\
\text { Mokwa e Varadarajan (1990); Souza e } \\
\text { Lara (2011) }\end{array}$ \\
\hline 16 & $\begin{array}{c}\text { Imagem da } \\
\text { empresa }\end{array}$ & $\begin{array}{l}\text { Cuida efetivamente da sua imagem } \\
\text { para que ela não seja percebida de } \\
\text { maneira distorcida pelo público } \\
\text { externo (clientes, fornecedores, } \\
\text { meios de comunicação e outros). }\end{array}$ & $\begin{array}{l}\text { Zeithaml e Zeithamal (1984); Conant, } \\
\text { Mokwa e Varadarajan (1990); Souza e } \\
\text { Lara (2011) }\end{array}$ \\
\hline 17 & Mercado & $\begin{array}{l}\text { Monitora eficazmente o preço } \\
\text { praticado pelos concorrentes. }\end{array}$ & $\begin{array}{l}\text { Tellis (1986); Conant, Mokwa e } \\
\text { Varadarajan (1990); Alves, Varotto e } \\
\text { Gonçalves (2012) }\end{array}$ \\
\hline 18 & Ponto de venda & $\begin{array}{l}\text { Está localizada em um ponto } \\
\text { estratégico que contribui para } \\
\text { atingir o público-alvo. }\end{array}$ & $\begin{array}{l}\text { Conant, Mokwa e Varadarajan (1990); } \\
\text { Doyle (2003) }\end{array}$ \\
\hline 19 & Processos & $\begin{array}{l}\text { Possui processos eficazes para } \\
\text { contenção de custos. }\end{array}$ & $\begin{array}{l}\text { Tellis (1986); Conant, Mokwa e } \\
\text { Varadarajan (1990) }\end{array}$ \\
\hline 20 & $\begin{array}{l}\text { Controle e } \\
\text { avaliação }\end{array}$ & $\begin{array}{l}\text { Controla e avalia sistematicamente } \\
\text { as atividades de marketing } \\
\text { desenvolvidas. }\end{array}$ & $\begin{array}{l}\text { Conant, Mokwa e Varadarajan (1990); } \\
\text { McDonald (1992). }\end{array}$ \\
\hline
\end{tabular}

Quadro 1 - Competências de marketing

Fonte: Adaptado de Conant, Mokwa e Varadarajan (1990).

Por isso, é importante compreender que as competências de marketing desempenham papel relevante na obtenção e manutenção da vantagem competitiva, devendo ser desenvolvidas internamente por meio de processos de aprendizagem, aplicação permanente e disseminação do conhecimento (VORHIES; HARKER, 2000). Bem como o desenvolvimento dessas competências possui um impacto reconhecido no desempenho da empresa, levando-a a níveis maiores de eficácia e à manutenção da sua 
vantagem competitiva no mercado (O’DISCROLL; CARSON; GILMORE, 2000).

\section{Metodologia}

Para alcançar o objetivo proposto neste estudo, optou-se por uma pesquisa quantitativa, descritiva e com corte transversal. Adotou-se a pesquisa quantitativa a fim de quantificar os dados coletados. A pesquisa descritiva, conforme Hair et al. (2005b, p.86) visa descrever e mensurar as características apresentadas em uma questão de pesquisa. E optou-se pelo corte transversal que, segundo Hair et al. (2005b, p.87), visa fornecer ao pesquisador um panorama ou uma descrição das informações em um dado ponto no tempo, e os dados tendem a ser coletados por meio de surveys, como ocorreu neste estudo.

Para tal, a população-alvo deste estudo foi composta por proprietários, diretores e gerentes/chefes de setor (formalmente designados ou não), pertencentes ao mercado varejista de produtos ou de serviços e que foram denominados como "gestores varejistas", podendo ser estes gestores em lojas físicas, virtuais ou vendas por catálogos, mas todos eram gestores em empresas varejistas, empresas estas que têm como foco vender produtos e/ou serviços para os consumidores finais. Desta forma, foi utilizada neste estudo uma amostra não probabilística por conveniência, visto que o varejo é muito amplo, com muitas empresas e o objetivo deste estudo permitiu a utilização deste tipo de amostragem.

Para a coleta de dados foi desenvolvido um questionário estruturado a partir da literatura sobre o tema, pois não foram identificados questionários específicos sobre o que se pretendeu mensurar nesta pesquisa. Desta forma, para atender ao objetivo proposto neste artigo, foi desenvolvido um questionário on-line que foi composto por 20 afirmações relativas às competências de marketing, sendo cada um destes atributos definidos no Quadro 2.

Quadro 2 - Escala proposta de competência de marketing

\begin{tabular}{|c|c|c|}
\hline \multirow{2}{*}{$\mathbf{N}$} & \multirow{2}{*}{ ATRIBUTO } & DESCRIÇÃO \\
\hline & & A empresa a que pertenço: \\
\hline 1 & Relação com o cliente & $\begin{array}{l}\text { Possui sólida relação com os clientes, que permite conhecê- } \\
\text { los profundamente. }\end{array}$ \\
\hline 2 & Concorrência & Conhece profundamente os concorrentes. \\
\hline 3 & Tendências do varejo & $\begin{array}{l}\text { Acompanha sistematicamente as tendências do mercado, } \\
\text { para conhecê-las previamente. }\end{array}$ \\
\hline 4 & Receita de vendas & $\begin{array}{l}\text { Prevê eficazmente as vendas dos produtos/serviços de seu } \\
\text { varejo. }\end{array}$ \\
\hline
\end{tabular}

Revista Eletrônica Gestão e Serviços v.8, n. 2, pp. 2080-2104, Julho/Dezembro 2017. ISSN Online: 2177-7284 e-mail: regs@metodista.br 


\section{GUSSO;MAINARDES; LAURETT}

\begin{tabular}{|c|c|c|}
\hline 5 & $\begin{array}{l}\text { Forças de marketing da } \\
\text { empresa }\end{array}$ & $\begin{array}{l}\text { Tem consciência dos seus pontos fortes ligados ao marketing } \\
\text { praticado. }\end{array}$ \\
\hline 6 & $\begin{array}{l}\text { Fraquezas de marketing da } \\
\text { empresa }\end{array}$ & $\begin{array}{l}\text { Tem consciência dos seus pontos fracos ligados ao } \\
\text { marketing praticado. }\end{array}$ \\
\hline 7 & Planejamento de marketing & $\begin{array}{l}\text { Possui capacidade técnica para desenvolver o planejamento } \\
\text { de marketing. }\end{array}$ \\
\hline 8 & Recursos para o marketing & $\begin{array}{l}\text { Destina recursos necessários (financeiros, tecnológicos, } \\
\text { humanos e estruturais) para que as atividades de marketing } \\
\text { possam ser desenvolvidas eficazmente. }\end{array}$ \\
\hline 9 & Integração de atividades & Integra as atividades de marketing às atividades de rotina. \\
\hline 10 & $\begin{array}{l}\text { Segmentação do público- } \\
\text { alvo }\end{array}$ & $\begin{array}{l}\text { Possui habilidade para dividir o público-alvo em grupos de } \\
\text { consumidores potenciais. }\end{array}$ \\
\hline 11 & $\begin{array}{l}\text { Benefícios do } \\
\text { produto/serviço }\end{array}$ & $\begin{array}{l}\text { Oferece produto/serviço atrativo e com benefícios além } \\
\text { daqueles esperados pelos clientes. }\end{array}$ \\
\hline 12 & Inovação em marketing & $\begin{array}{l}\text { Explora eficazmente as ideias inovadoras voltadas para a } \\
\text { venda de novos produtos/serviços. }\end{array}$ \\
\hline 13 & $\begin{array}{l}\text { Qualidade do } \\
\text { produto/serviço }\end{array}$ & $\begin{array}{l}\text { Oferece produto/serviço com qualidade superior à } \\
\text { concorrência. }\end{array}$ \\
\hline 14 & Preços do mercado & Monitora eficazmente o preço praticado pelos concorrentes. \\
\hline 15 & Promoção & $\begin{array}{l}\text { Desenvolve estratégias eficazes para divulgação do } \\
\text { produto/serviço. }\end{array}$ \\
\hline 16 & Relações públicas & $\begin{array}{l}\text { Interage eficazmente com o público externo (clientes, } \\
\text { fornecedores, meios de comunicação e outros). }\end{array}$ \\
\hline 17 & Imagem da empresa & $\begin{array}{l}\text { Cuida efetivamente da sua imagem para que ela não seja } \\
\text { percebida de maneira distorcida pelo público externo } \\
\text { (clientes, fornecedores, meios de comunicação e outros) }\end{array}$ \\
\hline 18 & Ponto de venda & $\begin{array}{l}\text { Está localizada em um ponto estratégico, que contribui para } \\
\text { atingir o público-alvo. }\end{array}$ \\
\hline 19 & Processos & Possui processos eficazes para contenção de custos \\
\hline 20 & Controle e avaliação & $\begin{array}{l}\text { Controla e avalia sistematicamente as atividades de } \\
\text { marketing desenvolvidas }\end{array}$ \\
\hline
\end{tabular}

Fonte: Elaborado pelos autores.

Complementarmente às afirmativas do questionário, solicitou-se ao respondente informações para caracterização da amostra, como o gênero, idade, escolaridade e cargo do respondente, além do setor de varejo da empresa pesquisada e classificação da empresa segundo o Banco Nacional do Desenvolvimento (BNDES, 2017). Para mensurar as respostas dos gestores varejistas quanto às competências de marketing, utilizou-se a escala de Likert de 7 pontos $(1=$ discordo totalmente; $7=$ concordo totalmente), que tendem a expressar melhor a intensidade dos sentimentos dos respondentes (HAIR et al., 2005a), se comparado com a escala de Likert de três ponto sutilizada por Snow e Hrebiniak (1980) para mensurar as competências de marketing.

Com o objetivo de aperfeiçoar e validar o instrumento, foi realizado um préteste, aplicando-se o questionário junto a 15 gestores varejistas. $\mathrm{O}$ processo de validação contribui para verificar se os gestores compreendiam as questões propostas no questionário ou tinham alguma dúvida; os participantes do pré-teste mencionaram que não tinham dúvidas, logo não foram realizadas alterações no questionário.

Revista Eletrônica Gestão e Serviços v.8, n. 2, pp. 2080-2104, Julho/Dezembro 2017.

ISSN Online: 2177-7284 e-mail: regs@metodista.br 


\section{GUSSO;MAINARDES; LAURETT}

Após a validação do questionário, iniciou-se a coleta de dados. Os questionários foram aplicados pessoalmente junto aos gestores varejistas que aceitaram espontaneamente participar da pesquisa. Foram visitadas, entre os dias 16/09/2013 e 08/03/2014, 265 empresas varejistas, sendo que em 66 houve recusa dos gestores em responder o questionário. Compreendeu-se que estes gestores recusaram-se a participar da pesquisa, em alguns casos por indisponibilidade e em outros casos por receio em fornecer informações. Ao finalizar o período de coleta de dados, chegou-se ao total de 199 questionários respondidos e válidos, os quais foram tabulados para a análise.

Para análise dos dados coletados, inicialmente, validou-se a amostra utilizada; a seguir, analisou-se a estatística descritiva, visando obter a média e o desvio padrão das variáveis estudadas. Optou-se pela análise da média, a fim de verificar as médias das percepções dos varejistas em relação a cada uma das competências de marketing. Em seguida, realizou-se a análise fatorial exploratória, visto que este tipo de análise mostrase a mais adequada para o alcance do objetivo proposto.

\section{Análise de dados}

\subsection{Caracterização da amostra}

Na Tabela 1, foram apresentadas as características (gênero, idade, escolaridade, cargo ocupado, setor do varejo e classificação da empresa) que possibilitaram a caracterização dos gestores varejistas e a verificação do enquadramento da amostra ao perfil da pesquisa. Ao final desta análise inicial, pode-se assumir que a amostra é adequada, pois apresenta o perfil do típico gestor varejista.

Tabela 1 - Caracterização dos gestores varejistas

\begin{tabular}{c|c|c|c}
\hline \multicolumn{2}{c|}{ CARACTERÍSTICAS } & FREQUÊNCIA & \% \\
\hline \multirow{2}{*}{ Gênero } & Masculino & 108 & 54,27 \\
& Feminino & 91 & 45,73 \\
\hline \multirow{4}{*}{ Idade } & $18-24$ & 19 & 9,54 \\
& $25-28$ & 20 & 10,05 \\
& $29-34$ & 56 & 28,15 \\
& $35-42$ & 57 & 28,64 \\
\multirow{4}{*}{ Escolaridade } & $>42$ & 47 & 23,62 \\
\hline & Ensino Fundamental & 7 & 3,52 \\
& Ensino Médio & 69 & 49,76 \\
& Ensino Superior & 14 & 33,67 \\
& Especialização & 10 & 7,03 \\
& Mestrado & 5,02 \\
\hline & Doutorado & \multicolumn{2}{c}{} \\
\hline
\end{tabular}

Revista Eletrônica Gestão e Serviços v.8, n. 2, pp. 2080-2104, Julho/Dezembro 2017. ISSN Online: 2177-7284 e-mail: regs@ metodista.br 
GUSSO;MAINARDES; LAURETT

\begin{tabular}{c|c|c|c} 
& Gerencial & 117 & 58,8 \\
Cargo ocupado na empresa & Proprietário & 80 & 40,2 \\
& Diretoria & 2 & 1 \\
\hline \multirow{2}{*}{ Setor do varejo } & Comércio & 147 & 73,87 \\
& Serviços & 52 & 26,13 \\
\hline \multirow{2}{*}{ Classificação da empresa } & Empreendedor individual (EI) & 20 & 10,05 \\
(cf. BNDES, 2017) & Microempresa & 98 & 49,25 \\
& Pequena empresa & 57 & 28,64 \\
& Média empresa & 11 & 5,53 \\
& Grande empresa & 13 & 6,53 \\
\hline
\end{tabular}

Fonte: Dados da pesquisa.

A partir da análise dos dados apresentados na Tabela 1, foi possível constatar que os gestores varejistas que participaram desse estudo foram, em sua maioria, do gênero masculino $(54,27 \%)$, com idade entre $35-42$ anos $(28,64 \%)$, possuem o ensino médio $(49,76 \%)$, ocupam cargo gerencial $(58,80 \%)$ e o setor do varejo comercial teve maior representatividade nesta amostra $(73,87 \%)$.

Destaca-se que 9,54\% da amostra ou 19 gestores tinham faixa etária entre 18 e 24 anos; isso deu-se ao fato de estarmos analisando um ramo que agregou diferentes classificações de empresas (de EI até grande empresa), e nestas empresas tendem a haver jovens empreendedores ou jovens que atuam como gestores em empresas familiares ou nas empresas dos seus próprios familiares.

Ainda quanto à idade, ressalta-se que o número de respondentes com idade entre 29-34 anos e com idade superior a 42 anos foi relevante, apresentando percentuais de $28,15 \%$ e $23,62 \%$, respectivamente. Somando-se os percentuais referentes ao componente "idade", constatou-se que $80,41 \%$ da amostra possui idade acima de 29 anos.

Pode-se verificar, também, que as microempresas representaram 49,5\% da amostra, as demais 51,5\% da amostra representaram as demais classificações de empresas (EI, pequena empresa, média empresa e grande empresa), e devido ao fato de ter-se obtido apenas 199 respostas nesta pesquisa, optou-se por não separar a amostra. Desta forma, sugere-se que pesquisas futuras possam realizar esta análise, averiguar as possíveis diferenças entre microempresa e as demais categorias em relação à percepção dos gestores varejistas quanto às competências de marketing.

Em suma, a partir dessa análise, foi possível validar a amostra da pesquisa, considerando que ela atende aos objetivos do estudo e apresenta o perfil do típico varejista; verificou-se uma conformidade da amostra desta pesquisa com um perfil típico identificado pelo Sebrae (2012) quanto ao sexo, idade e escolaridade, sendo a 


\section{GUSSO;MAINARDES; LAURETT}

maioria do sexo masculino, com idade média entre 35 e 49 anos; quanto à escolaridade, ensino médio completo/incompleto. Ressalta-se, ainda, que nesse estudo, para efeito da coleta e da análise de dados, na caracterização da amostra não foi realizada a distinção entre comércio varejista e comércio varejista ampliado.

\subsection{Estatística descritiva}

Para análise da estatística descritiva, optou-se por observar a média e o desvio padrão dos 20 atributos que representam as competências de marketing, conforme apresentado na Tabela 2. Pode-se aferir que as médias de todos os atributos explicativos (as 20 competências de marketing) ficaram acima de 4, ou seja, mesmo havendo divergências de concordância em relação a algumas variáveis explicativas (recursos para o marketing $-\mathrm{DP}=1,59$; fraquezas de marketing da empresa $-\mathrm{DP}=1,43$; forças de marketing da empresa $-\mathrm{DP}=1,42$; controle e avaliação $-\mathrm{DP}=1,40$ ), os gestores varejistas assumem possuir competências de marketing, bem como que realizam as atividades relacionadas às 20 competências de marketing.

Destaca-se que os percentuais de respostas das quatro variáveis que apresentaram médias acima de 6: imagem da empresa $(95,98 \%$ concordam totalmente; $1,50 \%$ discordam totalmente), qualidade do produto/serviço $(93,47 \%$ concordam totalmente; $1,50 \%$ discordam totalmente); ponto de venda $(88,94 \%$ concordam totalmente; 6,03\% discordam totalmente) e relações públicas (90,95\% concordam totalmente; 3,01\% discordam totalmente). Esses resultados demonstram que, na visão de seus gestores, as empresas varejistas pesquisadas detêm estas competências. Esses resultados convergem para os achados de Hooley et al. (2005), que afirmam que as empresas que possuem competências de marketing desenvolvem-se tendo como foco o mercado.

Tabela 2 - Estatística descritiva

\begin{tabular}{l|c|c}
\hline \multicolumn{1}{c|}{ ATRIBUTO } & MÉDIA & DESVIO PADRÃO \\
\hline $\mathbf{1}$ - Imagem da empresa & 6,31 & 0,9 \\
\hline $\mathbf{2}$ - Qualidade do produto/serviço & 6,20 & 0,96 \\
\hline $\mathbf{3}$ - Ponto de venda & 6,15 & 1,32 \\
\hline $\mathbf{4}$ - Relações públicas & 6,03 & 1,09 \\
\hline $\mathbf{5}$ - Benefícios do produto/serviço & 5,92 & 1,15 \\
\hline $\mathbf{6}$ - Preços de Mercado & 5,78 & 1,22 \\
\hline $\mathbf{7}$ - Relação com o cliente & 5,73 & 1,2 \\
\hline $\mathbf{8}$ - Receita de vendas & 5,72 & 1,13 \\
\hline $\mathbf{9}$ - Inovação em marketing & 5,72 & 1,28 \\
\hline
\end{tabular}

Revista Eletrônica Gestão e Serviços v.8, n. 2, pp. 2080-2104, Julho/Dezembro 2017.

ISSN Online: 2177-7284 e-mail: regs@ metodista.br 


\section{GUSSO;MAINARDES; LAURETT}

10 - Segmentação do público-alvo

11 - Promoção

12 - Tendências do varejo

13 - Processos

14 - Forças de marketing da empresa

15 - Concorrência

16 - Fraquezas de marketing da empresa

17 - Recursos para o marketing

18 - Integração de atividades

19 - Controle a avaliação

20 - Planejamento de marketing

Fonte: Dados da pesquisa.

Os resultados também convergem para os achados de Zeithaml e Zeithaml (1984), que afirmam que a empresa precisa tentar descobrir o que o consumidor deseja (relações públicas), estruturar os objetivos e as metas organizacionais para entregar o produto desejado de uma forma melhor do que a de seus concorrentes (qualidade do produto/serviço), resultando em credibilidade no mercado (imagem da empresa), que consequentemente influencia na qualidade percebida dos produtos/serviços oferecidos e nas decisões dos clientes (SOUZA; LARA, 2011).

Ressalta-se, ainda, que, mesmo apresentando média superior a 6, o desvio padrão da variável ponto de venda $(\mathrm{DP}=1,32)$ permite assumir que há heterogeneidade nas respostas dos gestores varejistas. Ainda assim, 88,94\% dos gestores varejistas afirmaram que sua empresa está localizada em um ponto estratégico, o que contribui para atingir seu público-alvo. Destaca-se que possuir essa competência de marketing é fundamental, pois é a partir da comunicação estabelecida entre o ponto de venda e o cliente que tende a ser gerada a legitimidade e a credibilidade de uma empresa (SOUZA; LARA, 2011).

Outra variável que merece destaque é relações públicas $(\mathrm{M}=6,03 ; \mathrm{DP}=1,09)$, pois refere-se à interação eficaz entre a empresa e o público externo (clientes, fornecedores, comunidade, meios de comunicação e outros). O resultado relativamente alto do desvio padrão sugere que não há consenso entre os gestores varejistas em relação a sua empresa possuir essa capacidade. Assim, considerando o mercado atual no qual a concorrência ocupa lugar de destaque (TOALDO; LUCE, 2006), torna-se necessário às empresas varejistas, que afirmaram não possuir tal competência $(9,05 \%$ discordam totalmente ou são indiferentes) que busquem formular e implementar estratégias de marketing que resultem no desenvolvimento dessa relação.

Já a variável recursos para o marketing apresentou alto desvio padrão (DP= 


\section{GUSSO;MAINARDES; LAURETT}

1,59), sugerindo que há divergências entre os gestores varejistas quanto a sua empresa possuir essa competência. Apesar disso, $71,35 \%$ dos gestores varejistas afirmaram que suas empresas destinam os recursos necessários para as atividades de marketing a serem desenvolvidas. Dada a sua importância para o marketing de varejo, é importante que os gestores varejistas que discordaram dessa afirmativa se apropriem dessa competência de marketing.

Por outro lado, observa-se ainda, na Tabela 2, que as variáveis controle e avaliação e planejamento de marketing possuem as menores médias (4,96 e 4,79, respectivamente) e desvioS padrão maiores que 1 (1,40 e 1,38, respectivamente), demonstrando que há divergências entre as respostas dos gestores varejistas em relação à capacidade de suas organizações para planejar o marketing da empresa $(64,32 \%$ concordam; 18,09\% discordam; 17,59\% são indiferentes), e em relação à sistematização do controle e da avaliação das atividades de marketing desenvolvidas (65,33\% concordam; 15,57\% discordam; 19,10\% são indiferentes).

Esses resultados sugerem um cenário preocupante, pois Brooksbank (1999) e Toften e Hammervoll (2010) afirmam que a vantagem competitiva sustentável de uma empresa está relacionada à sua capacidade de desenvolver planos de marketing eficazes e, de forma sistemática, controlar e avaliar as ações de marketing desenvolvidas, a partir do planejamento traçado (MCDONALD,1992), sendo estas as atividades menos assumidas pelos gestores pesquisados como realizadas pela sua empresa. Todavia, considerando que $83,42 \%$ dos gestores varejistas que participaram do estudo trabalham em PMEs e que, segundo Lancaster e Waddelow (1998), o planejamento é uma tarefa difícil para PMEs, pode-se compreender os resultados das variáveis em análise.

Entretanto, dada a sua importância estratégica, essas competências de marketing precisam ser desenvolvidas pelas empresas varejistas.

De maneira geral, a partir dos dados analisados, pode-se assumir que, na visão dos gestores varejistas das empresas pesquisadas, a imagem da loja $(M=6,31 ; D P=0,90)$ e a qualidade do produto/serviço $(M=6,20 ; \mathrm{DP}=0,96)$ são as duas principais competências de marketing que suas respectivas empresas possuem. Por meio desses resultados, podese admitir que, além de oferecer produtos/serviços com qualidade superior à concorrência, as empresas varejistas pesquisadas têm a preocupação de cuidar efetivamente da sua imagem, para que ela não seja percebida de maneira distorcida pelo público externo (clientes, fornecedores, meios de comunicação e outros). É evidente, 


\section{GUSSO;MAINARDES; LAURETT}

portanto, que essa visão dos gestores varejistas pode contribuir para manutenção da vantagem competitiva de suas empresas frente à concorrência e o aumento do desempenho financeiro do negócio (REIS NETO et al., 2013).

\subsection{Análise fatorial exploratória}

Para sintetizar as variáveis estudadas em um conjunto de fatores que exprimam o que as variáveis originais partilham em comum (HAIR et al., 2005a), optou-se por utilizar a análise fatorial exploratória. Foram utilizadas as 199 observações para reduzir as 20 variáveis representantes das competências de marketing, que, após a realização da rotação ortogonal, resultaram numa solução de quatro fatores (Tabela3).

Para validar a análise fatorial utilizou-se o índice KMO, que apresentou valor de 0,92. Esse teste define que os índices desejáveis são valores próximos de 1, assim, pode-se considerar que no presente estudo há uma relação ótima entre o tamanho da amostra e o número de variáveis. Outro teste utilizado, o de Bartlett, apresentou valor p $<0,01$, viabilizando, portanto, a utilização da análise fatorial.

Para a composição dos fatores, as variáveis foram distribuídas conforme a contribuição de cada uma na geração do fator, sendo dispostas em ordem decrescente de carga fatorial. A partir dessa composição, foi possível identificar o agrupamento entre as variáveis que se assemelham e a nomeação de cada fator com base nessa combinação das variáveis e com base na literatura científica abordada nesse estudo.

Baseando-se na sugestão de Comrey e Lee (1992), a carga fatorial dos componentes (Tabela 3) pode ser considerada "excelente" para os atributos mercado, benefícios do produto/serviço, relações públicas, imagem da empresa, planejamento de marketing, concorrência e ponto de venda. Sendo "muito boa" para os atributos inovação em marketing, recursos para o marketing, fraquezas de marketing da empresa, forças de marketing da empresa, integração de atividades, relação com o cliente e processos; "boa" para os atributos qualidade do produto/serviço, receita de vendas, promoção, controle e avaliação, tendências do varejo; e razoável para o atributo segmentação do público-alvo. Apesar do atributo segmentação do público-alvo mostrar carga fatorial razoável, ele não foi excluído, pois apresentou, na linha diagonal da matriz de correlações da anti-imagem, valor bem acima de 0,5 (segmentação do público-alvo $=0,940)$.

Revista Eletrônica Gestão e Serviços v.8, n. 2, pp. 2080-2104, Julho/Dezembro 2017. ISSN Online: 2177-7284 e-mail: regs@metodista.br 


\section{GUSSO;MAINARDES; LAURETT}

Quanto às comunalidades das variáveis (Tabela 3), constatou-se que os valores apresentados foram considerados satisfatórios, pois são $>0,50$, destacando-se o atributo ponto de venda, que apresentou uma contribuição de 0,89 , para geração do fator "estrutura e processo".

Tabela 3 -Matriz fatorial de componentes dos fatores

\begin{tabular}{|c|c|c|c|}
\hline FATOR (F) & ATRIBUTO DA VARIÁVEL & $\begin{array}{c}\text { CARGA } \\
\text { FATORIAL }\end{array}$ & COMUNALIDADES \\
\hline \multirow{8}{*}{$\begin{array}{c}\text { F1 } \\
\begin{array}{c}\text { Orientação para o } \\
\text { Mercado }\end{array}\end{array}$} & Mercado & 0,78 & 0,66 \\
\hline & Benefícios do produto/serviço & 0,77 & 0,76 \\
\hline & Relações públicas & 0,76 & 0,66 \\
\hline & Imagem da empresa & 0,75 & 0,61 \\
\hline & Inovação em marketing & 0,65 & 0,74 \\
\hline & Qualidade do produto/serviço & 0,6 & 0,65 \\
\hline & Receita de vendas & 0,59 & 0,58 \\
\hline & Promoção & 0,55 & 0,68 \\
\hline \multirow{7}{*}{$\begin{array}{c}\text { F2 } \\
\text { Capacidades } \\
\text { Internas }\end{array}$} & Planejamento de marketing & 0,86 & 0,76 \\
\hline & Recursos para o marketing & 0,69 & 0,64 \\
\hline & Fraquezas de marketing da empresa & 0,68 & 0,75 \\
\hline & Forças de marketing da empresa & 0,67 & 0,73 \\
\hline & Integração de atividades & 0,63 & 0,69 \\
\hline & Controle e avaliação & 0,59 & 0,66 \\
\hline & Segmentação do público-alvo & 0,51 & 0,67 \\
\hline \multirow{3}{*}{$\begin{array}{l}\text { F3 } \\
\text { Ambiente de } \\
\text { Negócios }\end{array}$} & Concorrência & 0,79 & 0,7 \\
\hline & Relação com o cliente & 0,65 & 0,64 \\
\hline & Tendências do varejo & 0,61 & 0,64 \\
\hline F4 & Ponto de venda & 0,89 & 0,8 \\
\hline Estrutura e processo & Processos & 0,65 & 0,67 \\
\hline
\end{tabular}

Fonte: Dados da pesquisa. Método de extração: PCA.

Analisando-se os quatro grupos apresentados na Tabela3, pode-se assumir que:

$\checkmark$ Fator "orientação para o mercado": agrega as competências de marketing relacionadas às variáveis (40\% das variáveis) que compõem o cenário externo do varejo, como, por exemplo, o mercado e o posicionamento. Por esse resultado assume-se que os gestores varejistas dão mais importância para as competências de marketing presentes nesse fator, sugerindo uma tendência à orientação para o mercado fundamental para a sobrevivência de uma organização varejista, o que corrobora com o estudo de Hooley et al. (2005).

Fator "capacidades internas": agrega as competências de marketing relacionadas às variáveis (35\% das variáveis) que compõem o cenário interno do varejo, como, por exemplo, o planejamento e os recursos de marketing. O resultado desse fator indica que os gestores varejistas 


\section{GUSSO;MAINARDES; LAURETT}

também se preocupam com as atividades relacionadas à prática interna do marketing, confirmando os estudos de Brooksbank (1999), Hooley et al. (2005) e de Davicik e Sharma (2016).

$\checkmark$ Fator "ambiente de negócios": agrega as competências de marketing relacionadas às variáveis $(15 \%$ das variáveis $)$ que compõem o relacionamento da empresa com o mercado: relação com o cliente, tendências de varejo e concorrência. Esse resultado converge para os achados de Lourenço e Sette (2013), os quais afirmam que possuir sólida relação com os clientes traz benefícios para ambas as partes (cliente e organização), sendo esta relação própria das empresas varejistas.

$\checkmark$ Fator "estrutura e processo": agrega as competências de marketing relacionadas às variáveis (10\% das variáveis) estrutura (ponto de venda) e o processo (custos) de um varejista. A partir dos resultados analisados, pode-se aferir que esse é um fator considerado menos importante pelos gestores varejistas, representando assim uma situação preocupante, pois, conforme destacado anteriormente, o ponto de venda é fundamental para se estabelecer a comunicação da empresa com o cliente (SOUZA; LARA, 2011).

$\mathrm{Na}$ Tabela4 são apresentados os quatro fatores gerados a partir da análise fatorial, seguidos dos percentuais de variância e variância acumulada e dos coeficientes Alfa de Cronbach.

Tabela 4 - Total da variância explicada

\begin{tabular}{l|c|c|c|c}
\hline \multirow{2}{*}{ FATOR } & \multicolumn{3}{|c|}{$\begin{array}{c}\text { SOMAS DA EXTRAÇÃO DE CARGAS AO } \\
\text { QUADRADO }\end{array}$} & $\begin{array}{c}\text { ALFA DE } \\
\text { CRONBACH }\end{array}$ \\
\cline { 2 - 5 } & Total & \% da Variância & $\begin{array}{c}\text { \%a Variância } \\
\text { Acumulada }\end{array}$ & \\
\hline Orientação para o mercado & 9,79 & $\mathbf{4 8 , 9 4}$ & 48,94 & 0,90 \\
\hline Capacidades internas & 1,73 & 8,66 & 57,6 & 0,91 \\
\hline Ambiente de negócios & 1,18 & 5,91 & 63,51 & - \\
\hline Estrutura e processo & 1,02 & 5,09 & $\mathbf{6 8 , 6}$ & - \\
\hline
\end{tabular}

Fonte: Dados da pesquisa. Método de extração: PCA.

Observa-se, a partir da Tabela 4, que a análise fatorial dos quatro fatores explica a variância de 68,60\%, sendo que os coeficientes Alfa de Cronbach dos fatores "orientação para o mercado", "capacidades internas" e "ambiente de negócios" apresentaram consistência interna adequada (valores $>0,5 \leq 1,0$ ), indicando fidedignidade dos fatores. Destaca-se que o fator "estrutura e processo" não apresenta o 


\section{GUSSO;MAINARDES; LAURETT}

coeficiente Alfa de Cronbach, pois as variáveis que o compõem são correlacionadas e, portanto, suficientes para validar o referido fator. Dessa forma, a estrutura fatorial obtida pôde ser validada, pois há homogeneidade entre os atributos.

O fator "orientação para o mercado", responsável por explicar 48,94\% da variância total do modelo, mostra que os gestores varejistas assumem que suas empresas possuem essas competências de marketing, o que, consequentemente, permite assumir que as empresas varejistas estudadas supostamente orientam-se para o mercado. Esse resultado converge com os achados de Zeithaml e Zeithaml (1984), Hooley et al. (2005) e Souza e Lara (2011).

Quanto ao fator "capacidades internas", este surge como o segundo mais relevante para os gestores varejistas, apresentando variância total de 8,66\% e agrupando os atributos referentes às atividades de marketing realizadas pelos lojistas. Tais atividades podem atrair e reter clientes, por meio do planejamento, recursos, segmentação e controles.

Os fatores "ambiente de negócios" (concorrência, relação com o cliente e tendências do varejo) e "estrutura e processo" (ponto de venda e processos) apresentam variância de 5,91\% e 5,09\%, respectivamente, indicando as competências de marketing que os gestores varejistas consideram menos importantes.

Para finalizar as análises, cabe destacar que o modelo fatorial obtido pode ser útil para identificar e medir as competências de marketing de um varejista, destacando os pontos fortes e fracos da própria loja, especialmente indicando o que é relevante ou não para a atração da loja, preparando adequadamente o gestor varejista para sua atuação no mercado. O quadro 3 apresenta o modelo final da análise fatorial exploratória por meio do agrupamento dos 20 atributos em quatro fatores de competências de marketing.

Quadro 3 - Fatores de competências de marketing no varejo

\begin{tabular}{|c|l|l|}
\hline \multirow{2}{*}{ FATOR (F) } & \multicolumn{1}{|c|}{$\begin{array}{c}\text { ATRIBUTO DA } \\
\text { VARIÁVEL }\end{array}$} & \multicolumn{1}{c|}{ DESCRIÇÃO DO ATRIBUTO } \\
\hline \multirow{2}{*}{$\begin{array}{c}\text { F1 Orientação } \\
\text { para o mercado }\end{array}$} & Mercado & $\begin{array}{l}\text { Monitora eficazmente o preço praticado pelos } \\
\text { concorrentes. }\end{array}$ \\
\cline { 2 - 3 } & Benefícios do produto/serviço & $\begin{array}{l}\text { Oferece produto/serviço atrativo e com } \\
\text { benefícios além daqueles esperados pelos } \\
\text { clientes. }\end{array}$ \\
\cline { 2 - 3 } & Relações públicas & $\begin{array}{l}\text { Interage eficazmente com o público externo } \\
\text { (clientes, fornecedores, meios de } \\
\text { comunicação e outros). }\end{array}$ \\
\hline
\end{tabular}

Revista Eletrônica Gestão e Serviços v.8, n. 2, pp. 2080-2104, Julho/Dezembro 2017. ISSN Online: 2177-7284 e-mail: regs@ metodista.br 
GUSSO;MAINARDES; LAURETT

\begin{tabular}{|c|c|c|}
\hline & Imagem da empresa & $\begin{array}{l}\text { Cuida efetivamente da sua imagem para que } \\
\text { ela não seja percebida de maneira distorcida } \\
\text { pelo público externo (clientes, fornecedores, } \\
\text { meios de comunicação e outros). }\end{array}$ \\
\hline & Inovação em marketing & $\begin{array}{l}\text { Explora eficazmente as ideias inovadoras } \\
\text { voltadas para a venda de novos } \\
\text { produtos/serviços. }\end{array}$ \\
\hline & Qualidade do produto/serviço & $\begin{array}{l}\text { Oferece produto/serviço com qualidade } \\
\text { superior à concorrência. }\end{array}$ \\
\hline & Receita de vendas & $\begin{array}{l}\text { Prevê eficazmente as vendas dos } \\
\text { produtos/serviços de seu varejo. }\end{array}$ \\
\hline & Promoção & $\begin{array}{l}\text { Desenvolve estratégias eficazes para } \\
\text { divulgação do produto/serviço. }\end{array}$ \\
\hline \multirow{7}{*}{$\begin{array}{l}\text { F2 Capacidades } \\
\text { internas }\end{array}$} & Planejamento de marketing & $\begin{array}{l}\text { Possui capacidade técnica para desenvolver o } \\
\text { planejamento de marketing. }\end{array}$ \\
\hline & Recursos para o marketing & $\begin{array}{l}\text { Destina recursos necessários (financeiros, } \\
\text { tecnológicos, humanos e estruturais) para que } \\
\text { as atividades de marketing possam ser } \\
\text { desenvolvidas eficazmente. }\end{array}$ \\
\hline & $\begin{array}{l}\text { Fraquezas de marketing da } \\
\text { empresa }\end{array}$ & $\begin{array}{l}\text { Tem consciência dos seus pontos fracos } \\
\text { ligados ao marketing praticado. }\end{array}$ \\
\hline & $\begin{array}{l}\text { Forças de marketing da } \\
\text { empresa }\end{array}$ & $\begin{array}{l}\text { Tem consciência dos seus pontos fortes } \\
\text { ligados ao marketing. praticado. }\end{array}$ \\
\hline & Integração de atividades & $\begin{array}{l}\text { Integra as atividades de marketing às } \\
\text { atividades de rotina. }\end{array}$ \\
\hline & Controle e avaliação & $\begin{array}{l}\text { Controla e avalia sistematicamente as } \\
\text { atividades de marketing desenvolvidas. }\end{array}$ \\
\hline & Segmentação do público-alvo & $\begin{array}{l}\text { Possui habilidade para dividir o público-alvo } \\
\text { em grupos de consumidores potenciais. }\end{array}$ \\
\hline \multirow{3}{*}{$\begin{array}{l}\text { F3 Ambiente de } \\
\text { negócios }\end{array}$} & Concorrência & Conhece profundamente os concorrentes. \\
\hline & Relação com o cliente & $\begin{array}{l}\text { Possui sólida relação com os clientes, que } \\
\text { permite conhecê-los profundamente. }\end{array}$ \\
\hline & Tendências do varejo & $\begin{array}{l}\text { Acompanha sistematicamente as tendências } \\
\text { do mercado, para conhecê-las previamente. }\end{array}$ \\
\hline \multirow{2}{*}{$\begin{array}{l}\text { F4 Estrutura e } \\
\text { processo }\end{array}$} & Ponto de venda & $\begin{array}{l}\text { Está localizada em um ponto estratégico, que } \\
\text { contribui para atingir o público-alvo. }\end{array}$ \\
\hline & Processos & $\begin{array}{l}\text { Possui processos eficazes para contenção de } \\
\text { custos. }\end{array}$ \\
\hline
\end{tabular}

Fonte: Elaborado pelos autores

Pode-se perceber que estes quatro fatores tendem a explicar os 20 atributos de marketing do comércio varejista. O primeiro fator denominado "orientação para o mercado" é composto por oito atributos. Este fator tende a agrupar os atributos relativos à análise de mercado no qual o varejo está inserido, focando na análise dos preços praticados pela concorrência, nos benefícios que os produtos e/ou serviços tendem a oferecer aos clientes, análise e monitoramento da imagem e marca da empresa. E ainda 


\section{GUSSO;MAINARDES; LAURETT}

estarem atentos à qualidade dos produtos e serviços oferecidos, investir em estratégias inovadoras de marketing, fazer a previsão de vendas e como divulgar os produtos e/ou serviços.

O segundo fator foi denominado "capacidades internas" e composto por oito atributos. Analisa as empresas varejistas a partir das suas capacidades internas, sobre o seu planejamento de marketing, recursos financeiros, tecnológicos, humanos e estruturais para desenvolver as atividades de marketing, para realizar a análise interna das forças e fraquezas, integrar o marketing na rotina da empresa e se realizam o controle e avaliação das atividades de marketing.

O terceiro fator tem três atributos e foi chamado de "ambiente de negócios". Este fator visa focar em uma análise profunda dos concorrentes e dos clientes e acompanha sistematicamente as tendências do mercado. $\mathrm{O}$ último fator foi denominado como "estrutura e processo", e foi composto por dois atributos. Este fator tem como foco analisar se o comércio varejista está localizado em um ponto de venda estratégico a fim de atingir seu público-alvo e se os seus processos são eficazes na contenção de custos.

Por fim, todos estes quatro fatores devem ser levados em consideração pelas empresas varejistas, pois estes tendem a gerar uma diferenciação neste mercado cada vez mais competitivo, onde as competências de marketing devem ser utilizadas para captar novos clientes e buscar manter os atuais. E, ainda, tratando-se do comércio varejista, onde em muitos casos os produtos vendidos tendem a ser iguais, ou no mínimo muito similares, a questão que cabe aos gestores varejistas analisar é: como posso me diferenciar dos concorrentes? Por outro lado, atualmente, há uma diversidade muito grande de produtos, logo, cabe aos gestores varejistas buscarem conhecer cada vez mais quem são seus clientes, para oferecer a estes os produtos e serviços conforme as suas necessidades.

\section{Conclusão}

Esse estudo teve como objetivo principal identificar os fatores que compõem as competências de marketing no varejo, sendo que, para alcançá-los, foram realizados o levantamento e a análise de vinte variáveis apresentadas no estudo de Conant, Mokwa e Varadarajan (1990) e que representam as referidas competências de marketing. Em seguida, foram definidos atributos para essas competências a partir da revisão dos 


\section{GUSSO;MAINARDES; LAURETT}

estudos de Constantinides (2006), de Souza e Lara (2011), de Toni et al. (2011) e de Lourenço e Sette (2013). A partir disso, os atributos foram agrupados em quatro fatores por meio da análise fatorial exploratória, que sistematizou as competências de marketing do varejo.

Os resultados dos dados coletados por meio do questionário estruturado aplicado junto a 199 gestores varejistas leva a concluir que os gestores assumem que as suas empresas possuem competências de marketing e que as desenvolvem com foco no mercado. Esta afirmação pode ser observada no fator "orientação para o mercado", o que agrega $40 \%$ dos atributos das competências de marketing e que compõem o cenário externo do varejo, como, por exemplo, o mercado e a imagem.

Além disso, de maneira geral, infere-se que os gestores varejistas das empresas pesquisadas consideram a imagem da loja e a qualidade do produto/serviço como principais competências de marketing de suas empresas. Este resultado constatado tende a ser pela preocupação dos gestores varejistas em cuidar efetivamente da imagem da empresa, visando manter sua vantagem competitiva frente à concorrência e aumentar o desempenho financeiro de sua organização.

Diante desses resultados, pode-se assumir que o estudo contribuiu para a teoria, a partir do agrupamento dos 20 atributos das competências de marketing no setor varejista em quatro fatores, não ter estudado apenas no setor supermercadista, mas ter focado comércio varejista e comércio varejista ampliado, o que fornece uma percepção mais geral deste setor. E também por ter estudado diferentes classificações de empresas varejistas, (empreendedores individuais, microempresas, pequenas empresas, médias empresas e grandes empresas).

$\mathrm{Na}$ prática, estes fatores podem ser utilizados pelos gestores varejistas para identificar as competências de marketing que as empresas varejistas possuem e as que precisam ser desenvolvidas. Estas informações tendem a ser de grande utilidade para estas empresas. Os resultados desta pesquisa também podem ser utilizados pelos setores de recursos humanos das empresas varejistas para analisar novos investimentos em treinamento e desenvolvimento e para elaboração de novos planos de marketing. Considera-se que, a partir desta pesquisa, na qual foi realizado um agrupamento, os gestores não necessitarão analisar os 20atributos individualmente para compreender as competências de marketing, mas é possível analisá-los a partir dos quatro fatores (orientação para o mercado, capacidades internas, ambiente de negócios, estrutura e 
processo).

Entretanto, este estudo possui limitações, como: os resultados representam a percepção dos gestores varejistas num determinado momento e, com o passar do tempo, essa opinião pode alterar. É importante destacar que nem tudo que os varejistas assumiram executar, realmente, está sendo realizado em suas lojas, afinal o que foi medido foram as percepções dos gestores varejistas. Além disso, pode haver outras competências de marketing que não foram abordadas por essa pesquisa, considerando que foram estudadas somente as vinte variáveis que representam as competências de marketing, conforme estudo de Conant, Mokwa e Varadarajan (1990). Finalmente, os resultados não podem ser generalizados, considerando que foi utilizado uma amostra não probabilística (por conveniência).

Recomenda-se que pesquisas futuras testem a estrutura fatorial obtida neste estudo em segmentos específicos do varejo, como, por exemplo, o varejo de serviços, e em empresas de grande porte, visando conhecer as competências de marketing de classificações diferenciadas de empresas. Também é importante recomendar que estudos futuros sejam realizados buscando compreender em profundidade as percepções dos gestores varejistas em relação às competências de marketing, considerando que essas competências também são importantes para que a empresa possa desenvolver vantagem competitiva sustentável. Sugere-se, por fim, que pesquisas futuras possam realizar uma análise das possíveis diferenças entre microempresas e as demais categorias de empresas quanto à percepção dos gestores em relação às competências de marketing.

\section{Referências}

ALVES, Carlos Alberto; VAROTTO, Luiz Fernando; GONÇALVES, Marcelo Neves. Objetivos e métodos de preço no varejo: estudo na zona sul de São Paulo. Revista de Administração de Empresas, São Paulo, v. 52, n. 6, p. 595-612, 2012.

AMBLER, Tim. Marketing metrics. Business Strategy Review, v. 11, n. 2, p. 59-66, 2000.

BANCO NACIONAL DO DESENVOLVIMENTO (BNDES). Porte de empresas. Disponível em: https://www.bndes.gov.br/wps/portal/site/home/financiamento/guia/porte-de-empresa Acesso em 22. Dez. 2017. 
BARKI, Edgard; BOTELHO, Delane; PARENTE, Juracy. Varejo: desafios e oportunidades em mercados emergentes. Revista de Administração de Empresas, São Paulo, v. 53, n. 6, p. 534-538, 2013.

BROOKSBANK, Roger. The theory and practice of marketing planning in the smaller business. Marketing Intelligence \& Planning, v. 17, n. 2, p. 78-91, 1999.

BURT, Steve; SPARKS, Leigh. E-commerce and the retail process: a review. Journal of Retailing and Consumer Services, v. 10, n. 5, p. 275-286, 2003.

CARSON, David. Marketing for small-to-medium enterprises. In: BAKER, M. J (Org.). The Marketing Book.5. ed. Oxford: Butterworth-Heinemann, 2003. p. 621-638.

COMREY, A. L.; LEE, H. B. A First Course in Factor Analysis. 2 ed. New York : Psychology Press, 1992.

CONANT, Jeffrey S.; MOKWA, Michael P.; VARADARAJAN, P. Rajan. Strategic types, distinctive marketing competencies and organizational performance: a multiple measures-based study. Strategic management journal, v. 11, n. 5, p. 365-383, 1990.

CONSTANTINIDES, Efthymios. The marketing mix revisited: towards the 21st century marketing. Journal of marketing management, v. 22, n. 3-4, p. 407-438, 2006.

COUSINS, Laura. Marketing plans or marketing planning?. Business Strategy Review, v. 2, n. 2, p. 35-54, 1991.

DAVCIK, Nebojsa S.; SHARMA, Piyush. Marketing resources, performance, and competitive advantage: A review and future research directions. Journal of Business Research, v. 69, n. 12, p. 5547-5552, 2016.

DAY, George $\mathrm{S}$. The capabilities of market-driven organizations. Journal of Marketing, v. 58, n. 4, p. 37-52, oct. 1994.

DELOITTE. Os poderosos do varejo global: sem fronteiras em um ambiente multicanal. 2013. Disponível em: <http://www2.deloitte.com/br/pt/pages/consumerbusiness/articles/global-powers-of-retailing-2013.html>. Acesso em: 5 jun. 2014.

DIBB, Sally. Market segmentation: strategies for success. Marketing Intelligence \& Planning, v. 16, n. 7, p. 394-406, 1998.

DOYLE, Peter. Managing the marketing mix. In: Baker, M. J (Org.). The Marketing Book.5. ed. Burlington: Butterworth-Heinemann, 2003. p. 293-441.

FARHANGMEHR, Minoo; MARQUES, Susana; SILVA, Joaquim. Consumer and retailer perceptions of hypermarkets and traditional retail stores in Portugal. Journal of Retailing and Consumer Services, v. 7, n. 4, p. 197-206, 2000.

GUENZI, Paolo; TROILO, Gabriele. Developing marketing capabilities for customer 
value creation through Marketing-Sales integration. Industrial marketing management, v. 35, n. 8, p. 974-988, 2006.

GUMMESSON, Evert. The new marketing-developing long-term interactive relationships. Long range planning, v. 20, n. 4, p. 10-20, aug. 1987.

HAIR, Joseph F. et al. Análise multivariada de dados. Porto Alegre: Bookman, 2005a.

HAIR, Joseph F. et al. Fundamentos de métodos de pesquisa em administração. Bookman Companhia Ed, 2005b.

HART, S. New product development. In: BAKER, M. J. The Marketing Book. 5. ed. Burlington: Butterworth-Heinemann, 2003. p. 314-341.

HOOLEY, Graham J. et al. The performance impact of marketing resources. Journal of Business Research, v. 58, n. 1, p. 18-27, 2005.

INDOUNAS, Kostis; AVLONITIS, George J. Pricing objectives and their antecedents in the services sector. Journal of Service Management, v. 20, n. 3, p. 342-374, 2009.

INSTITUTO BRASILEIRO DE GEOGRAFIA E ESTATÍSTICA. Comércio. 2017. Disponível em: <https://brasilemsintese.ibge.gov.br/comercio.html〉. Acesso em: 9 out. 2017.

INSTITUTO BRASILEIRO DE GEOGRAFIA E ESTATÍSTICA. Pesquisa Mensal de Comércio. 2013. Disponível em: 〈http://www.ibge.gov.br/home/estatistica/indicadores/comercio/pmc/>. Acesso em: 5 jun. 2014.

LANCASTER, Geoff; WADDELOW, Ian. An empirical investigation into the process of strategic marketing planning in SMEs: its attendant problems, and proposals towards a new practical paradigm. Journal of Marketing Management, v. 14, n. 8, p. 853-878, 1998.

LEVITT, Theodore. Marketing success through differentiation-of anything. Harvard:Graduate School of Business Administration, Harvard University, 1980.

LOURENÇO, Cléria Donizete da Silva; SETTE, Ricardo de Souza. Relacionamentos de marketing em empresas varejistas: aspectos positivos e negativos. REMark, São Paulo, v. 12, n. 3, p. 152, 2013.

MCDONALD, Malcolm HB. Strategic marketing planning: a state-of-the-art review. Marketing Intelligence \& Planning, v. 10, n. 4, p. 4-22, 1992.

MELAIA, Stuart; ABRATT, Russell; BICK, Geoff. Competencies of marketing managers in South Africa. Journal of Marketing Theory and Practice, v. 16, n. 3, p. 233-246, 2008.

NOWAK, Glen J.; PHELPS, Joseph. Conceptualizing the integrated marketing 
communications' phenomenon: An examination of its impact on advertising practices and its implications for advertising research. Journal of Current Issues \& Research in Advertising, v. 16, n. 1, p. 49-66, 1994.

O'DRISCOLL, Aidan; CARSON, David; GILMORE, Audrey. Developing marketing competence and managing in networks: a strategic perspective. Journal of strategic marketing, v. 8, n. 2, p. 183-196, 2000.

PANIGYRAKIS, George G.; THEODORIDIS, Prokopis K. Market orientation and performance: An empirical investigation in the retail industry in Greece. Journal of Retailing and Consumer Services, v. 14, n. 2, p. 137-149, 2007.

PARENTE, J. Varejo no Brasil: gestão e estratégia. Ed. 1. São Paulo: Atlas, 2007.

QUEIROZ, Tatiana Silva de; SOUZA, Tereza de; GOUVINHAS, Reidson Pereira. Estratégia de marketing como um diferencial na escolha do supermercado de bairro. Revista de Administração Mackenzie, São Paulo, v. 9, n. 3, p. 58-84, 2008.

RAMAKRISHNAN, K. The competitive response of small, independent retailers to organized retail: Study in an emerging economy. Journal of Retailing and Consumer Services, v. 17, n. 4, p. 251-258, 2010.

RAMARAO, Ravulaparthy. Competitiveness of India's Micro and Small Enterprises through Functional Competencies: Role in Nation's Development. Vikalpa, v. 37, n. 1, p. $97-112,2012$.

REIS NETO, José Francisco dos et al. As conexões entre orientação empreendedora, capacidade de marketing e a percepção do desempenho empresarial: evidências empíricas das micro e pequenas empresas varejistas. RAM - Revista de

Administração Mackenzie, São Paulo, v. 14, n. 3, edição especial, p. 236-271, maio/jun. 2013.

SEBRAE. Um retrato do empreendedor do varejo brasileiro. 2012. Disponível em: $<$ https://www.sebrae.com.br/Sebrae/Portal\%20Sebrae/Anexos/Estudo_Perfil_do_em preendedor.pdf $>$. Acesso em: 15 out. 2017.

SMIGIELSKA, Grazyna; WISNIEWSKA, Sylwia. Marketing Innovations in Retail Trade. Problemy Zarzadzania-Management,v.14, n.1, p.57-70, 2016.

SNOW, Charles C.; HREBINIAK, Lawrence G. Strategy, distinctive competence, and organizational performance. Administrative Science Quarterly, v. 25, n. 2, p. 317336, june 1980.

SOUZA, Ronaldo Barbosa de; LARA, José Edson. Imagem de loja: proposição de escala para o segmento varejista farmacêutico. BBR-Brazilian Business Review, v. 8, n. 1, p. 74-93, 2011.

TELLIS, Gerard J. Beyond the many faces of price: an integration of pricing strategies. Journal of Marketing,v. 50, n. 4, p. 146-160, 1986. 
TOALDO, Ana Maria Machado; LUCE, Fernando Bins. Estratégia de Marketing: contribuições para a teoria de marketing. Revista de Administração de Empresas, São Paulo, v. 46, n.4, p. 25-35, 2006.

TOFTEN, Kjell; HAMMERVOLL, Trond. Niche marketing and strategic capabilities: an exploratory study of specialised firms. Marketing Intelligence \& Planning, v. 28, n.6, p. 736-753, 2010.

TOLEDO, Geraldo Luciano; NEVES, Marcos Fava; MACHADO FILHO, Cláudio A. Pinheiro. Marketing Estratégico e Varejo: o caso europeu. Revista de administração, São Paulo, v. 32, n. 2, p. 47-57, 1997.

TONI, Deonir de et al. A Imagem do Comércio Varejista e a satisfação dos consumidores: um estudo exploratório ambientado em uma cidade da Serra Gaúcha.

Revista de Administração e Contabilidade, São Leopoldo, v. 8, n. 1, p. 91-104, 2011.

VORHIES, Douglas W.; HARKER, Michael. The Capabilities and Perfor Mance Advantages of Market-Driven Firms: An Empirical Investigation. Australian journal of management, v. 25, n. 2, p. 145-171, 2000.

WIRTZ, Bernd W.; PELZ, Richard; ULLRICH, Sebastian. Marketing competencies of publishers and ad sales success: An empirical analysis. Journal of Media Business Studies, v. 8, n. 1, p. 23-46, 2011.

WOODSIDE, Arch G.; SULLIVAN, Daniel P.; TRAPPEY, Randolph J. Assessing relationships among strategic types, distinctive marketing competencies, and organizational performance. Journal of Business research, v. 45, n. 2, p. 135-146, 1999.

ZEITHAML, Carl P.; ZEITHAML, Valarie A. Environmental management: revising the marketing perspective. The Journal of Marketing, v. 48, n. 2, p. 46-53, 1984.

ZEN, R. Modelo de diagnóstico do atendimento no comércio varejista de pequeno porte. 2005. 230 f. Tese (Doutorado em Engenharia de Produção). Universidade Federal de Santa Catarina - UFSC. Florianópolis, 2005. 